\section{THEORETICAL RESEARCH ON THE STABILITY OF THE TRANSPORT MODULE INTENDED FOR TRANSPORT FROM THE SEABED}

DOI 10.2478/ntpe-2018-0076

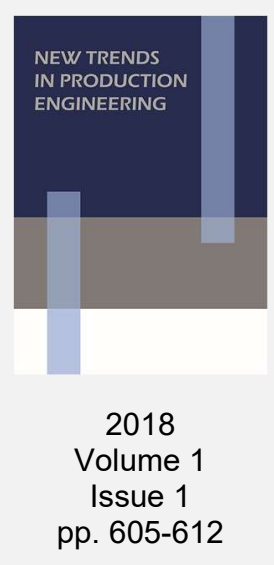

\begin{abstract}
The interest in sea mining has resulted in the recent years in the creation of many new methods for the exploitation of marine deposits as well as the transport from the seabed to the. For several years, the authors have been trying to develop new concepts of transport from the seabed. In previous publications, the authors presented the concept of an autonomous transport module for transport from the seabed. The research so far has focused on the development of the module's operation principles, determination of the energy source in the transport process and changes in the average density of the transport module. In this publication, the authors focused on the stability problem of the transport module during deployment and ascent. This is a very important issue, because the stability of the module will determine its practical suitability for transport from the seabed.
\end{abstract}

Keywords: Marine mining, transport from great depths, autonomous transport module

\title{
INTRODUCTION
}

The growing interest in deep-sea mining has led in recent years to the emergence of many new methods for the exploitation of deep-sea deposits and the transport of output from the sea bottom to the surface (Karlic, 1984; Depowski et al., 1998, Sobota, 2005, Abramowski and Kotliński, 2011, SPC, 2013, Sharma, 2017). For several years, studies have been underway to develop a new concept of sea-bottom transport.

In our previous publications, we presented the results of previous studies of the concept of an autonomous transport module for sea-bottom transport (Filipek and Broda, 2016, 2017). These studies focused on developing the module's principle of operation and identifying the source of energy in the transport process, and changes to the average density of the transport module.

In this publication, we addressed the problem of the transport module's stability during immersion and surfacing. This is a very important subject, since the module's stability will determine whether it is viable as a means of sea-bottom transport.

The equilibrium of floating bodies is very important from the practical point of view (e.g. with regard to structures of vessels). It has been the subject of numerous studies (Walden and Stasiak, 1971; Roberson and Crowe, 1995; Kobyliński and Kastner 2003; Pawłowski, 2016; Kobyliński, 2018) and technical solutions, which describe these problems comprehensively. In our case, due to the way in which the transport module works, we must consider two cases of stability: a floating body and an immersed body.

As a rule, a floating body will remain in a state of balance when the body weight $G$ is equal to the buoyancy force $\mathrm{W}$ and the centre of gravity $S_{c}$ and the centre of buoyancy $S_{w}$ lie on the same vertical axis called the float axis (Walden and Stasiak, 1971). When the centre of gravity $S_{c}$ lies below the centre of buoyancy $S_{w}$, the body remains in stable equilibrium. An interesting situation takes place when the centre of gravity $S_{c}$ lies above the centre of buoyancy $S_{w}$. The equilibrium will be stable when the body, displaced by a momentary external force, returns to equilibrium. Vertical axis rotation and horizontal displacement have no effect on equilibrium. Vertical displacement, in turn, changes only the buoyancy force, without changing its vector. When moved around its horizontal axis, the body can be permanently displaced from equilibrium. 
To define the stability criterion, we introduced the following notions: the metacentre $M$, which is the point at the intersection of the float axis and the line which is aligned with the buoyant-force vector and perpendicular to the floating plane and the metacentric height $\mathrm{m}$ being the distance between the metacentre $M$ and the centre of gravity $S_{c}$. When the metacentre and centre of gravity lie in the same point $(m=0)$, the body is in neutral equilibrium; when the metacentre $M$ is above the centre of gravity $S_{c}$, i.e. when $m>0$, the floating body is in static equilibrium - it is stable; when the metacentric height $m<0$, i.e. $M$ lies below the centre of gravity $S_{c}$, the body is in unstable equilibrium, i.e. it is not static.

In the case of fully immersed bodies, the situation depends on how the centre of gravity $S_{c}$ and centre of buoyancy $S_{w}$ are located in relation to each other. If the centre of gravity $S_{c}$ lies below the centre of buoyancy $S_{w}$, the immersed body is static - it is in stable equilibrium. When the centre of gravity lies above the centre of buoyancy, the immersed body is unstable it is in unstable equilibrium. When the locations of the centre of gravity and centre of buoyancy overlap, we have neutral equilibrium.

Our task is to determine the (location) coordinates of the centre of gravity and metacentre of the transport module with a pre-defined geometry (of a cylinder sized $L$ and $\Phi$ ) as a function of the location of the centre of buoyancy, in order for the vessel to remain stable.

\section{DETERMINING THE LOCATION OF THE CENTRE OF BUOYANCY OF A CYLINDER- SHAPED TRANSPORT MODULE}

The key parameter determining the stability of an object is the location of the centre of buoyancy. Its coordinates depend on the environment surrounding the object. By determining these coordinates, we can identify the location of the metacentre, thus allowing us to design the transport module correctly, so that the location of the centre of gravity allows the module to remain stable throughout the transport process.

From all the shapes of transport containers considered by many researchers (Karlic, 1984; Depowski et al., 1998, Sobota, 2005, SPC, 2013, Sharma, 2017), a cylinder is the simplest. Therefore, we will rely on its geometry in our study. In order to determine the spatial coordinates $S_{w}, S_{c}$ i $M$ for a cylinder, we only need to identify two parameters $y$ and $z$, as defined in Fig. 1 and 2.

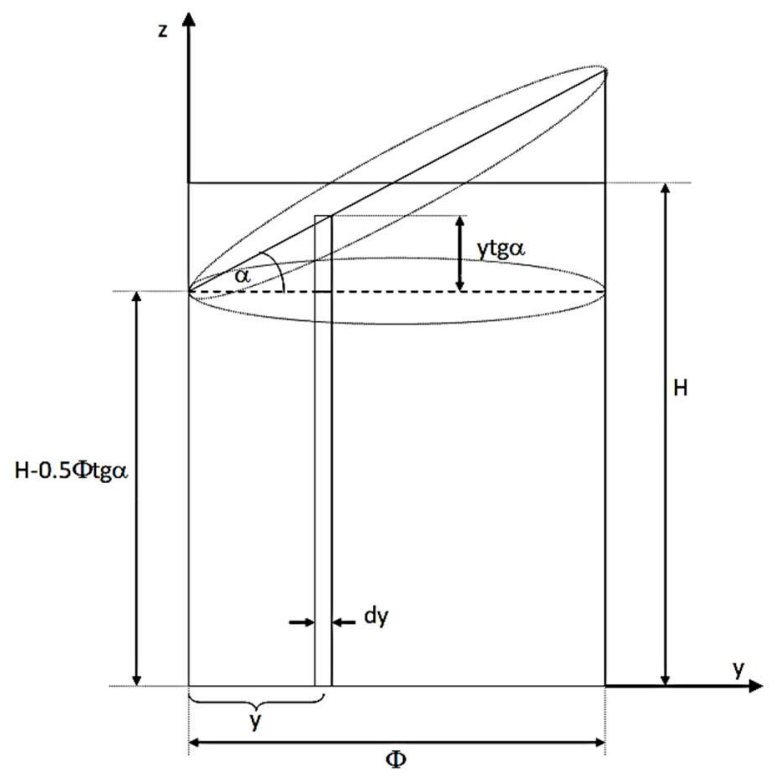

Fig. 1. Graphical interpretation of the method to determine the coordinate $S_{y}$ of the centre of buoyancy.

The parameter $z$ (coordinate) is related to the cylinder height. In our study, its length corresponds to the distance from the base of the cylinder along the axis $z$ (Fig. 1 and 2). The coordinate $y$ is a parameter that defines the distance measured along the cylinder's diameter 
from the axis $\mathrm{z}$ crossing the cylinder's side-wall (Fig. 1 and 2). In our study, the parameter $\mathrm{H}$ denotes the body's immersion in relation to the water surface, measured in relation to the cylinder's axis of symmetry perpendicular to the base and water surface. For the floating body $0 \leq \mathrm{H} \leq \mathrm{L}$, while for the immersed body $\mathrm{H}=\mathrm{L}$. The angle $\alpha$ is the angle between the original and momentary floating surface.

Let us start by determining the coordinate $y$ of the centre of buoyancy $S_{y}$ using the method illustrated in Fig. 1 below.

To determine the relationship which identifies the coordinate $S_{w y}$, we will use the known relationship (1)

$$
\mathrm{S}_{\mathrm{wy}}=\frac{\int y d V}{\int d V}
$$

By expanding the denominator of expression (1), we obtain the following relationship (2).

$$
\int d V=2 \int_{0}^{\varnothing}[H+\operatorname{tg} \alpha(y-0.5 \Phi)] \sqrt{y(\Phi-y)} d y=\frac{\pi}{4} \Phi^{2} \mathrm{H}=\mathrm{V}
$$

The numerator of the equation (1) is presented as relationship (3)

$$
\int y d V=2 \int_{0}^{\varnothing} y[H+\operatorname{tg} \alpha(y-0.5 \Phi)] \sqrt{y(\Phi-y)} d y=\frac{\pi}{64} \Phi^{3}[8 \mathrm{H}+\Phi \operatorname{tg} \alpha]
$$

By using relationships (2) and (3) in (1), we obtain the target coordinate $S_{w y}$ in the form of (4)

$$
S_{w y}=\frac{\Phi[8 \mathrm{H}+\Phi \operatorname{tg} \alpha]}{16 \mathrm{H}}
$$

If the cylinder-shaped transport module is not tilted, i.e. $\alpha=0$, then the coordinate $S_{w y}=0.5, \Phi$, which is intuitively predictable and confirms that the employed calculation method is correct.

Another parameter to be determined is the coordinate of the centre of buoyancy $S_{w z}$. We will determine it on the basis of the known relationship (5)

$$
S_{w z}=\frac{\int z d V_{1}+\int z d V_{2}+\int z d V_{3}}{\int d V_{1}+\int d V_{2}+\int d V_{3}}
$$

The calculation method employed is illustrated in the figure below (Fig. 2).

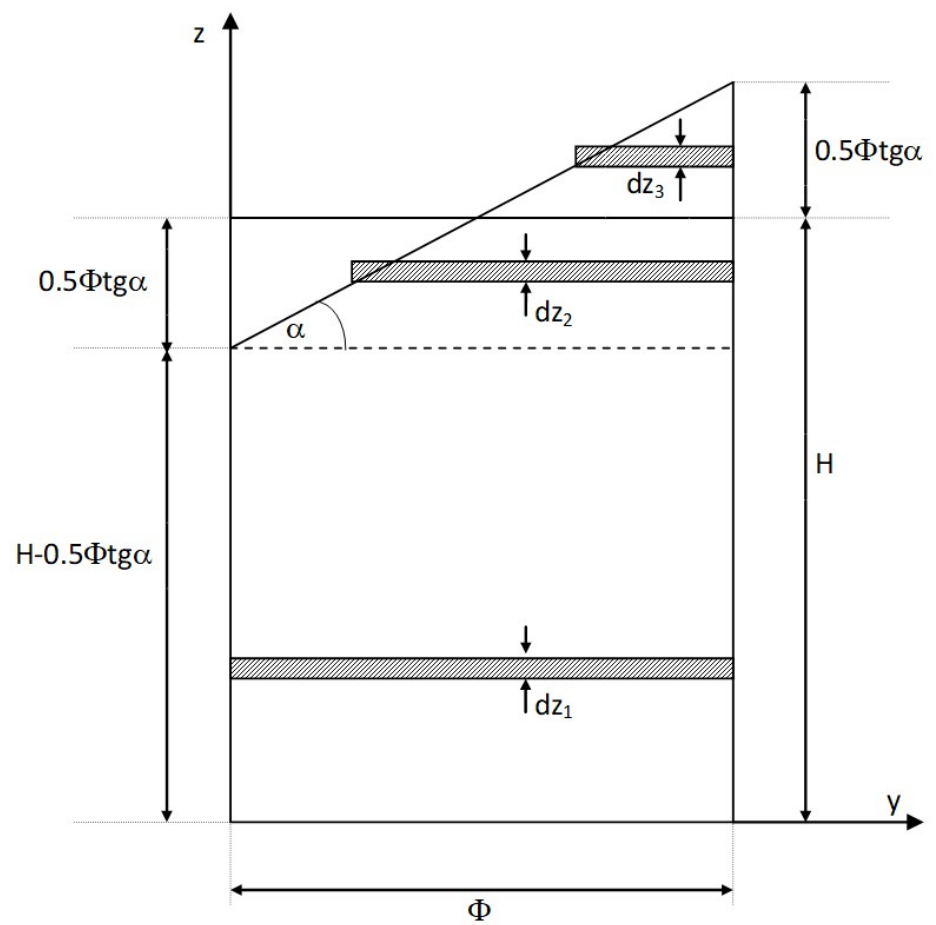

Fig. 2. Graphical interpretation of the method to determine the coordinate $S_{z}$ of the centre of buoyancy.

Based on the above Fig. 2, the individual components of the above equation (5) will have the following form after expansion (6):

$$
\int d V_{1}=\int_{0}^{H-0.5 \Phi \operatorname{tg} \alpha} \pi \frac{\Phi^{2}}{4} d z=\frac{\pi \Phi^{2}}{4}\left(H-\frac{\Phi}{2} \operatorname{tg} \alpha\right)
$$




$$
\begin{gathered}
\int d V_{2}=\int_{0}^{0.5 \Phi \operatorname{tg} \alpha}\left\{\pi-\frac{\pi}{360} 2 \arccos \left(1-\frac{2 z}{\Phi \operatorname{tg} \alpha}\right)+\frac{1}{2} \sin \left[2 \arccos \left(1-\frac{2 z}{\Phi \operatorname{tg} \alpha}\right)\right]\right\} d z \\
\int d V_{3}=\int_{0}^{0.5 \Phi \operatorname{tg} \alpha}\left\{\frac{\pi}{360} 2 \arccos \left(\frac{2 z}{\Phi \operatorname{tg} \alpha}\right)-\frac{1}{2} \sin \left[2 \arccos \left(\frac{2 z}{\Phi \operatorname{tg} \alpha}\right)\right]\right\} d z \\
\int z d V_{1}=\int_{0}^{H-0.5 \Phi \operatorname{tg} \alpha} \pi \frac{\Phi^{2}}{4} z d z=\pi \frac{\Phi^{2}}{8}\left(H-\frac{\Phi}{2} \operatorname{tg} \alpha\right)^{2} \\
\int z d V_{2}=\int_{0}^{0.5 \Phi \operatorname{tg} \alpha} z \frac{\Phi^{2}}{4}\left\{\pi-\frac{\pi}{360} 2 \arccos \left(1-\frac{2 z}{\Phi \operatorname{tg} \alpha}\right)+\frac{1}{2} \sin \left[2 \arccos \left(1-\frac{2 z}{\Phi \operatorname{tg} \alpha}\right)\right]\right\} d z \\
\int z d V_{3}=\int_{0}^{0.5 \Phi \operatorname{tg} \alpha} z \frac{\Phi^{2}}{4}\left\{\frac{\pi}{360} 2 \arccos \left(\frac{2 z}{\Phi \operatorname{tg} \alpha}\right)-\frac{1}{2} \sin \left[2 \arccos \left(\frac{2 z}{\Phi \operatorname{tg} \alpha}\right)\right]\right\} d z
\end{gathered}
$$

Hence, after conversion, the result is

$$
\int d V_{1}+\int d V_{2}+\int d V_{3}=\frac{1}{4} \pi \Phi^{2} H
$$

While

$$
\int z d V_{1}+\int z d V_{2}+\int z d V_{3}=\frac{1}{4} \Phi^{2}\left\{\frac{1}{2} \pi H^{2}+\Phi \operatorname{tg} \alpha\left[\Phi \operatorname{tg} \alpha\left(\frac{9}{32} \pi-\frac{1}{6}\right)-\frac{1}{2} \pi H\right]\right\}
$$

By substituting (5) with the expressions (7) and (8), we obtain the target relationship identifying the coordinate $S_{w y}$ of the centre of buoyancy:

$$
S_{w Z}=\frac{\frac{1}{2} \pi H^{2}+\Phi \operatorname{tg} \alpha\left[\Phi \operatorname{tg} \alpha\left(\frac{9}{32} \pi-\frac{1}{6}\right)-\frac{1}{2} \pi H\right]}{\pi H}
$$

Assuming that the original and momentary floating surface overlap, i.e. $\alpha=0$, then the centre of buoyancy coefficient $S_{z}=1 / 2 \mathrm{H}$, meaning that our reasoning is correct.

\section{THE LOCATION OF THE TRANSPORT MODULE'S METACENTRE}

When considering vessels floating on the surface, the key parameter defining the stability of such vessels is the location of the metacentre $M$, determined using the method provided in (Walden and Stasiak, 1971), and converting the resulting stability for our purposes, as illustrated in Figure 3, where: $W(y, z)$ is the location of the centre of buoyancy for $\alpha=0$, and $W^{\prime}(y, z)$ is the new location of the centre of buoyancy after being displaced from equilibrium by an angle of $\alpha$. The $Z$ quantity is the location of the metacentre $M$ in relation to the centre of buoyancy $\mathrm{W}$, measured along the float axis $Z$.

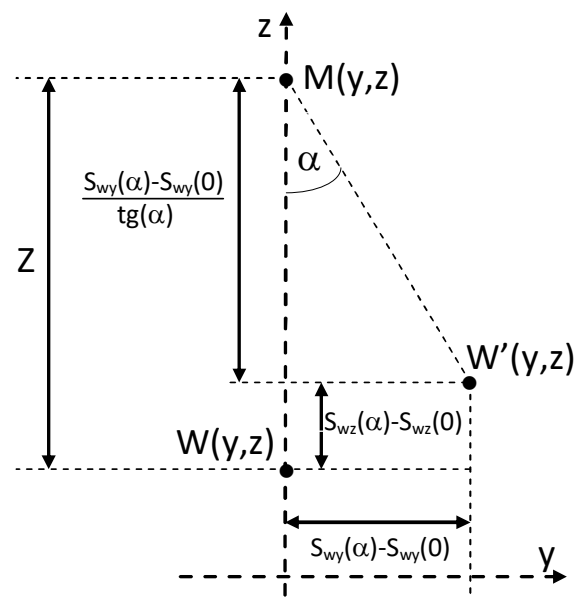

Fig. 3. Graphical interpretation of the method to locate the metacenter.

The $Z$ quantity is determined using the geometric relationships shown in Figure 3:

$$
Z=S_{w z}(\alpha)-S_{w z}(0)+\frac{S_{w y}(\alpha)-S_{w y}(0)}{\operatorname{tg} \alpha}
$$

By adding the relationships (4) and (9) to the above formula, we obtain:

$$
Z=\frac{9}{32} \frac{\Phi^{2}}{\mathrm{H}} \operatorname{tg}^{2}(\alpha)-\frac{1}{6} \frac{\Phi^{2}}{\pi \mathrm{H}} \operatorname{tg}^{2}(\alpha)-\frac{1}{2} \Phi \operatorname{tg}(\alpha)+\frac{1}{16} \frac{\Phi^{2}}{\mathrm{H}}
$$

When analysing the equation (11), it is easily noticeable that $Z$ is a function of all three parameters $H \Phi$ and $\alpha$. To arrive at the universal form of the equation (11), allowing us to analyse it without constraints as to parameters, let us define the coefficient $\beta(n, \alpha)$ fulfilling the condition $\mathrm{Z}(\mathrm{H}, \Phi, \alpha)=\beta(\mathrm{n}, \alpha) \mathrm{H}$. 
Accordingly, let us now adopt a simple relationship in which the cylinder's diameter depends on the cylinder's height in the form of $\Phi=n H$, where $n$ is the dimensionless proportionality coefficient. After including this in the above relationship (1), we obtain:

$$
Z=\frac{9}{32} n^{2} \operatorname{Htg}^{2}(\alpha)-\frac{1}{6} n^{2} \frac{H}{\pi} \operatorname{tg}^{2}(\alpha)-\frac{1}{2} n H \operatorname{tg}(\alpha)+\frac{1}{16} n^{2} H
$$

Next, by dividing the equation (12) by $\mathrm{H}$, we obtain the following relationship (13):

$$
\frac{Z}{H}=\beta(n, \alpha)=\frac{\mathrm{n}}{96}\left(27 \mathrm{ntg}^{2}(\alpha)-16 \frac{\mathrm{n}}{\pi} \operatorname{tg}^{2}(\alpha)-48 \operatorname{tg}(\alpha)+6 \mathrm{n}\right)
$$

The above dimensionless expression allows us to determine the transport module's metacentre (in the form of a cylinder) for any $\mathrm{H}$.

\section{THE LOCATION OF THE TRANSPORT MODULE'S CENTRE OF GRAVITY}

Knowing the location of the metacentre $\mathrm{M}$, we can identify the location of the centre of gravity $S_{c}$ ensuring that the hypothetical transport module is stable. To this end, we only need to analyse the sequence of the equation $\beta$ (13).

The location of the centre of gravity $S_{c}$ is characterised by two coordinates $S_{c z}$ and $S_{c y}$, described as in the following relationships:

$$
\begin{aligned}
& S_{c z}=H-\min (\beta) H \\
& S_{c y}=S_{w y}
\end{aligned}
$$

where:

$\min (\beta)$ is the lowest value of the function $\beta(\mathrm{n}, \alpha)$.

Now, let us convert the function $\beta$ (13) into a simpler form (16), and determine the zeroes.

$$
\beta(n, \alpha)=\mathrm{n}\left[\mathrm{n}\left(27-\frac{16}{\pi}\right) \operatorname{tg}^{2}(\alpha)-48 \operatorname{tg}(\alpha)+6 \mathrm{n}\right]=0
$$

If we consider the relationship (16) as a square function of the variable $\alpha$ with the parameter $n$, then from a mathematical point of view, there are always two zeroes. A simpler method to solve the equation (16) involves the assumption that $n$ is the variable and the parameter is $\alpha$. Accordingly, this involves e a product of two linear functions, giving us only one solution $n(\alpha)$ in the form of (17), as presented graphically in Fig. 4.

$$
\beta(n, \alpha)=0<=>n(\alpha)=\frac{48 \operatorname{tg}(\alpha) \pi}{\operatorname{tg}^{2}(\alpha)(27 \pi-16)+6 \pi} \text { dla } \alpha \in\left[0, \frac{\pi}{2}\right)
$$

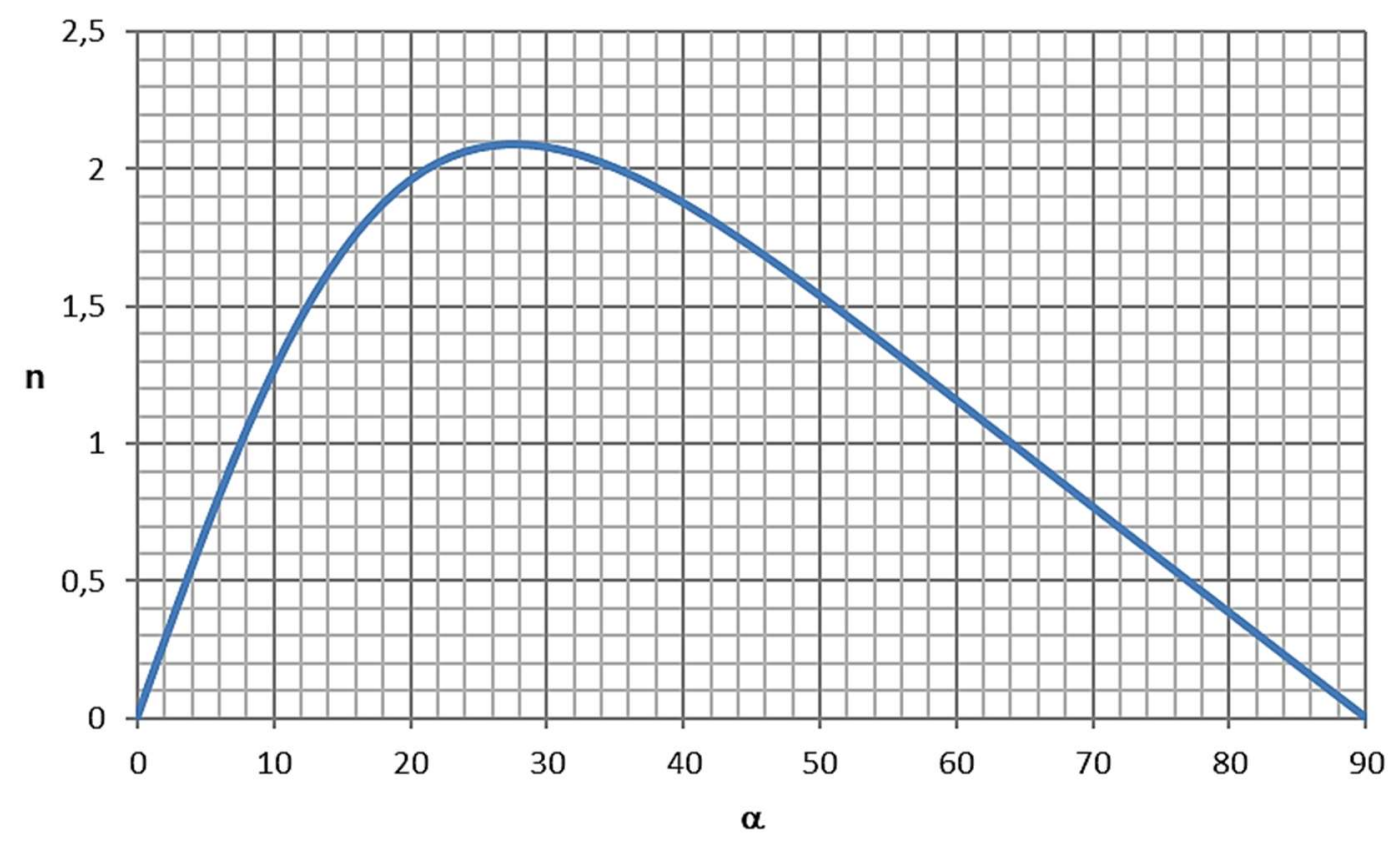

Fig. 4 Graphical interpretation of the solution to the equation (16). 
Fig. 5 illustrates the relationship between the coefficient $\beta$ and the angle $\alpha$ for selected values of the coefficient. Depending on the parameter $\mathrm{n}$, the function $\beta(\mathrm{n}, \alpha)$ has one zero, which is the extreme of the function $n(\alpha)(17)$.

$$
\frac{d n(\alpha)}{d \alpha}=0<=>\alpha=\left\{\begin{array}{c}
\operatorname{arctg} \sqrt{\frac{6 \pi}{(27 \pi-1)}}=>\left\{\begin{array}{c}
\alpha=27.625 \\
n=2,093
\end{array}\right. \\
-\operatorname{arctg} \sqrt{\frac{6 \pi}{(27 \pi-16)}}<0
\end{array}\right.
$$

Above the extreme $\operatorname{dn}(\alpha) / d \alpha=0$, the function $\beta(n, \alpha)$ does not have any zeroes in the set of $R$ numbers. Below the extreme, it has two zeroes.

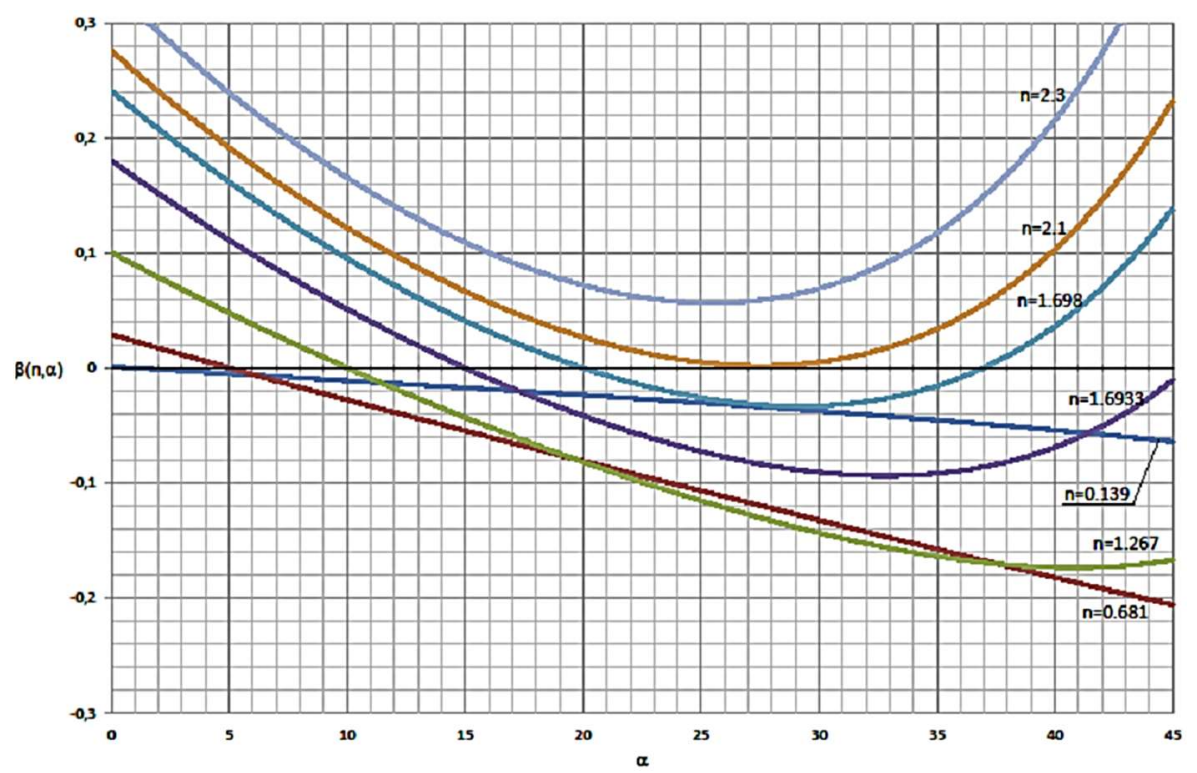

Fig. 5. Graphical interpretation of the dimensionless coefficient $\beta$ for selected $n$.

When analysing the curves in the figure above, we can notice that the function $\beta(n, \alpha)$ must have an extreme. This extreme is, in actuality, the sought value $\min (\beta)$. To find its value, we calculate the first derivative of the function (13) due to the variable $\alpha$, equating it to zero:

$$
\min (\beta)=\frac{\partial \beta(n, \alpha)}{\partial \alpha}=\frac{n}{48}\left(1+\operatorname{tg}^{2}(\alpha)\right)\left[\mathrm{n}\left(27-\frac{16}{\pi}\right) \operatorname{tg}(\alpha)-24\right]=0
$$

By solving the above equation (19), we obtain:

$$
\min (\beta)=\frac{\partial \beta(n, \alpha)}{\partial \alpha}=0<=>\left\{\begin{array}{c}
n=0 \\
n(\alpha)=\frac{24}{27 \pi-1} \operatorname{tg}^{-1}(\alpha) \text { dla } \alpha \in\left(0, \frac{\pi}{2}\right)
\end{array}\right.
$$

The graphical illustration of the solution to the equation (19) is provided in Fig. 6.

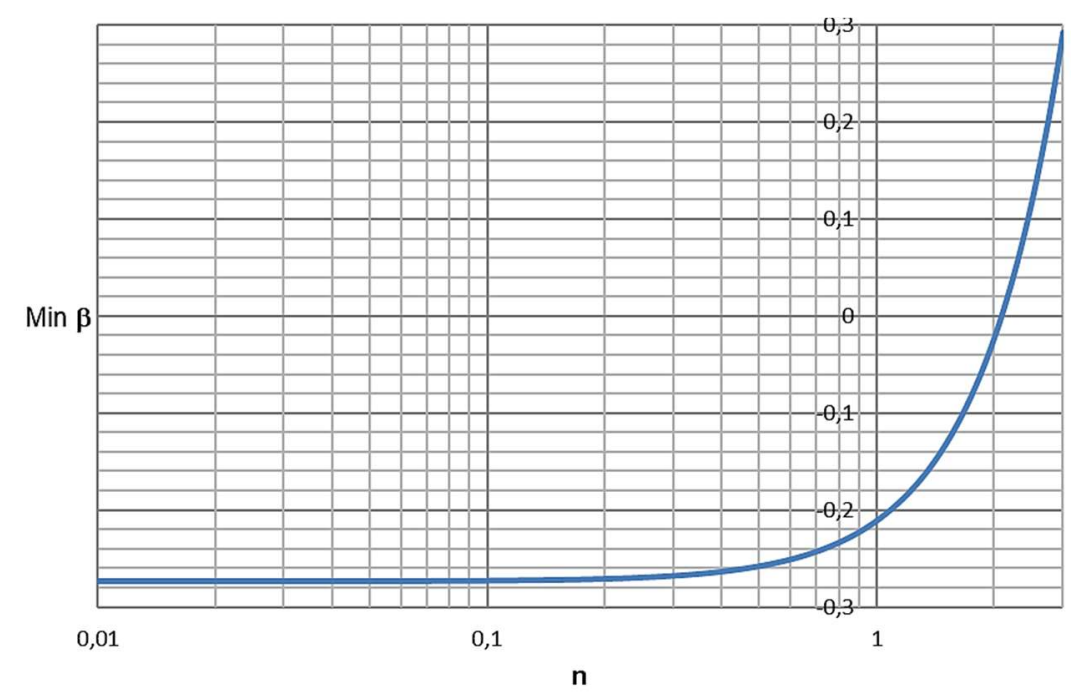

Fig. 6. Graphical interpretation of the solution to the equation (18). 


\section{CONCLUSIONS}

In our experimental study related to a concept of designing an autonomous transport module, we have encountered a problem involving the stability of a model transport module. This inspired us to address the problem, resulting in the present publication. The behaviour of the model transport module we observed during our experiments is reflected in our theoretical study.

By defining the dimensionless function $\beta$ (13), we can comprehensively and clearly analyse the stability of the hypothetical model transport module for any cylinder dimensions $(L, \Phi)$. By knowing $\beta$, we can identify the range of location of the transport module's centre of gravity for which the module remains stable. This knowledge is very important for designing and building the transport module.

Following an analysis of the curves in Fig. 5 , we concluded that it is of key importance to know $\min (\beta)(19)$ as the function $\mathrm{n}$. In actuality, $\mathrm{n}$ must be lower than 1 in the design of the transport module $n$. The analysis of the curve in Fig. 6 leads us to the observation that for each value $\mathrm{n} \leq 1 \min (\beta)$ is lower than zero. This means that the centre of gravity must be below the centre of buoyancy.

If the stability conditions (14) and (15) are satisfied for a floating, immersing object $(0<\mathrm{H} \leq \mathrm{L})$, then they are also satisfied after full immersion.

The presented method to determine the stability of a cylinder-shaped autonomous transport module for sea-bottom transport can be applied for shapes with lower hydrodynamic resistances. Based on these theoretical findings, we will design and build a prototype of an autonomous transport module. We believe that the module will be suitable for testing at sea.

\section{ACKNOWLEDGMENTS}

This article was written within Statutes Research AGH, No. 11.11.100.005

\section{REFERENCES}

Abramowski T., Kotliński R. (2011), Współczesne wyzwania eksploatacji oceanicznych kopalin polimetalicznych, Górnictwo i geoinżynieria, Rok 35, zeszyt 5, pp.41-61.

Depowski, S., Kotliński R., Rühle E., Szamałek K. (1998), Surowce mineralne mórz i oceanów, Wydawnictwo Naukowe Scholar, Warszawa.

Filipek W., Broda K. (2016), Theoretical foundation of the implementation of controlled pyrotechnical reactions as an energy source for transportation from the sea bed, Scientific Journals of the Maritime University of Szczecin, 48 (120), 117-124.

Filipek W., Broda K. (2017), The Theoretical Basis of the Concept of Using the Controlled Pyrotechnical Reaction Method as an Energy Source in Transportation from the Sea Bed, TransNav the International Journal on Marine Navigation and Safety of Sea Transportation, Vol.11, No. 4, 653-659.

Karlic S. (1984), Zarys górnictwa morskiego, Wydawnictwo „Śląsk”, Katowice

Kobyliński L., Kastner S. (2003), Stability and safety of ships, Vol. I, Elsevier

Kobyliński L. (2018), New Generation Stability Norms - How to Approach the Task, Polish Maritime Research, Special Issue 2018 S1 (97), Vol. 25; pp. 56-62 10.2478/pomr-20180023

Pawłowski M. (2016), Stateczność statku swobodnie pływającego, Polski Rejestr Statków, Raport Techniczny $\mathrm{nr}$ 71, Raport końcowy, Gdańsk, Available from: https://www.prs.pl/_files/parent347/tr_no_71.pdf [Accesed 12 July 2018]

Roberson, J.A., Crowe, C.T. (1995), Engineering Fluid Mechanics. John Wiley \& Sons, Inc.

Sharma, R. (2017), Deep-Sea Mining: Resource Potential, Technical and Environmental Considerations, Springer International Publishing AG, Cham

Sobota J. et. al. (2005), Systemy i technologie wydobycia konkrecji z dna oceanów. Zeszyty Naukowe Akademii Rolniczej we Wrocławiu nr 521, Monografie XLIII, Seria: Współczesne problemy inżynierii środowiska. Wrocław

SPC (2013), Deep Sea Minerals: Sea-Floor Massive Sulphides, a physical, biological, environmental, and technical review. Baker, E., and Beaudoin, Y. (Eds.) Vol. 1A, Secretariat of the Pacific Community, ISBN 978-82-7701-119-6, Available from: http://gsd.spc.int/dsm/public/files/meetings/ [Accesed 12 July 2015]

TrainingWorkshop4/UNEP_vol1A.pdf 
Walden H., Stasiak J. (1971), Mechanika cieczy i gazów w inżynierii sanitarnej, Warszawa, Arkady

Date of submission of the article to the Editor: 07/2018

Date of acceptance of the article by the Editor: 09/2018 